\title{
PRODUKTIVITAS TENAGA KERJA KELUARGA PADA USAHA SAPI BALI TERINTEGRASI PERKEBUNAN KELAPA SAWIT DI KECAMATAN WIWIRANO KABUPATEN KONAWE UTARA
}

\author{
La Ode Arsad Sani ${ }^{1}$, Laode Muh Munadi ${ }^{* 1}$, Musram Abadi ${ }^{1}$, Alfiansyah ${ }^{1}$ \\ Muhammad Amrullah Pagala ${ }^{1}$, Natsir Sandiah ${ }^{1}$ \\ Jurusan Peternakan, Fakultas Peternakan, Universitas Halu Oleo \\ e-mail: *1Immunadi@gmail.com
}

\begin{abstract}
The development of beef cattle farms can be done through an integrated system and the involvement of family labor. The objective of this study is to know the family labor productivity in the integrated Bali cattle business and palm oil plantations in Wiwirano District, North Konawe Regency. The research material is breeders in the District of Wiwirano who carry out the integration efforts of Bali cattle and palm oil, as many as 4 villages in Wiwirano district, that integrated the Bali cattle and oil palm were determined by stratified sampling. 60 respondents from 4 villages were selected using simple random sampling. The average allocation of family labor in the Bali cattle business reaches 5,635 hours/day or 0,653 HOK/day. While the allocation of family labor in the palm oil business reaches 10,121 hours/day or 1,151 HOK. The technical productivity of the Bali cattle business is 4,72 ST/HOK and economic productivity is Rp 83.983,43/HOK. While the technical productivity of the oil palm plantation business is $133,69 \mathrm{~kg} / \mathrm{HOK}$ and economic productivity is $R p$ 120.772,75/HOK.
\end{abstract}

Keywords: Labor, Bali Cattle, Palm Oil.

\section{PENDAHULUAN}

Sistem integrasi ternak sapi-kelapa sawit adalah perpaduan antara dua sektor yaitu peternakan dan pertanian yang keduanya sama-sama saling menguntungkan (Pagala et al., 2020). Legum dan limbah yang ada di perkebunan kelapa sawit dapat dimanfaatkan sebagai pakan ternak sapi (Pagala, 2019). Sebaliknya, feses yang dihasilkan oleh ternak sapi dapat dimanfaatkan sebagai pupuk kompos untuk meningkatkan kesuburan dan produksi kelapa sawit (Zulkarnain et al., 2020). Di satu sisi, ternak sapi bertindak sebagai bioindustri dan juga sebagai pemberantas gulma yang ada di kebun kelapa sawit (Fadli \& Satriawan, 2018).

Keterlibatan tenaga kerja keluarga dalam sektor usaha peternakan sapi potong, berperan penting dalam meningkatkan produktivitas ekonomi keluarga (Rusnan et al., 2015). Olehnya itu kemampuan manajerial setiap anggota keluarga sangat menentukan efisiensi dalam memanfaatkan faktor produksi baik dalam usaha tani maupun usaha ternak (Setiawan et al., 2019). Tujuan pokok dari sebuah usaha tani keluarga adalah untuk memperoleh hasil setinggi mungkin guna mencukupi kebutuhan bagi pelaksanaan usaha taninya dan pembentukan modal (Sirait et al., 2015). Selain berusaha tani peternak juga memiliki usaha tani lain untuk mendukung usahanya. 
Produktivitas tenaga kerja di sektor pertanian ditentukan oleh ketersediaan faktor-faktor sarana produksi, investasi atau penggunaan teknologi serta aktivitas yang dilakukan oleh tenaga kerja itu sendiri (Efendi et al., 2020). Perhitungan produktivitas tenaga kerja adalah membagi kuantitas hasil dengan kuantitas penggunaan masukan tenaga kerja, dimana masukan tenaga kerja dapat dihitung dalam jam kerja setara pria (JKSP), hari orang kerja (HOK), ataupun dalam perhitungan waktu kerja satu tahun (Anggara, 2019).

Kabupaten Konawe Utara merupakan salah satu kabupaten yang potensial untuk pengembangan ternak sapi di Provinsi Sulawesi Tenggara dan tahun 2017 memiliki populasi 9.873 ekor. Selain ternak sapi, petani di Kabupaten Konawe Utara juga memiliki lahan perkebunan kelapa sawit dengan luas lahan kelapa sawit sebesar 456 Ha. Kecamatan Wiwirano merupakan salah satu kecamatan di Kabupaten Konawe Utara yang memiliki populasi ternak sapi sebanyak 2.329 ekor dan luas lahan kelapa sawit sebesar 290 Ha serta 187 orang peternak (BPS Konawe Utara, 2020). Namun demikian keterpaduan pengelolaan usaha ternak sapi dengan usahatani kelapa sawit yang terintegrasi belum banyak dikaji, termasuk peran tenaga kerja keluarga untuk mendukung pengembangan usaha ternak sapi dan usahatani kelapa sawit di Kabupaten Konawe Utara. Oleh karena itu penelitian ini bertujuan untuk menganalisis "Produktivitas Tenaga Kerja Keluarga Usaha Sapi Bali yang Terintegrasi dengan Perkebunan Kelapa Sawit di Kecamatan Wiwirano Kabupaten Konawe Utara”.

\section{METODE PENELITIAN}

Penelitian ini dilakukan September-November 2020 di Kecamatan Wiwirano Kabupaten Konawe Utara Provinsi Sulawesi Tenggara. Penelitian ini menggunakan metode survei dengan penentuan lokasi secara sengaja (purposive sampling), yaitu memilih Kecamatan Wiwirano dengan alasan bahwa peternak di wilayah ini memiliki usaha kombinasi perkebunan kelapa sawit dan usaha ternak sapi Bali paling banyak di Kabupaten Konawe Utara. Penetapan desa lokasi penelitian dipilih 4 desa dan mengambil 15 orang dari masingmasing desa sehingga keseluruhan responden berjumlah 60 orang.

Data primer adalah data yang diperoleh langsung dari responden petani peternak sapi sekaligus melakukan usaha tani perkebunan kelapa sawit berdasarkan daftar pertanyaan yang telah disiapkan. Data sekunder adalah data yang diperoleh dari instansi terkait baik dari Badan Pusat Statistik, Dinas Peternakan, kepustakaan dan laporan atau hasil penelitian sebelumnya. Variabel penelitian yang diamati pada penelitian ini adalah karakteristik responden meliputi (umur, pendidikan formal, pengalaman beternak/bertani dan jenis pekerjaan). Selanjutnya variabel berikutnya berupa curahan waktu tenaga kerja keluarga dan produktivitas tenaga kerja keluarga yang meliputi produktivitas teknis dan produktivitas ekonomis. Model analisis yang digunakan adalah produktivitas teknis dan produktivitas ekonomis (Tatipikilawan 2012):

- Produktivitas Teknis Tenaga Kerja

$$
\text { Produktivitas Teknis }=\frac{\text { Jumlah Panen }(S T)}{\text { Curahan Tenaga Kerja }(\mathrm{HOK})}
$$

- Produktivitas Ekonomis Tenaga Kerja

$$
\text { Produktivitas Ekonomis }=\frac{\operatorname{Upah}(\mathrm{R} p)}{\text { Curahan Tenaga Kerja }(\mathrm{HOK})}
$$

1. Curahan tenaga kerja laki-laki = Jumlah jam kerja laki-laki $\mathrm{x}$ JKSP

2. Curahan tenaga kerja perempuan = Jumlah jam kerja perempuan $\mathrm{x}$ JKSP

3. Curahan tenaga kerja anak = Jumlah Jam Kerja Anak x JKSP 
SEA Volume 10, No. 01, June 2021

Dimana : JKSP = Satuan jam kerja setara pria dewasa (1 JKSP), Untuk wanita dewasa $=0,8 \mathrm{JKSP}$ sedangkan untuk anak-anak $=0,5 \mathrm{JKSP}$.

\section{HASIL DAN PEMBAHASAN}

\section{Karakteristik Peternak}

Karakteristik peternak digunakan untuk mengetahui keragaman responden berdasarkan umur, pendidikan, pekerjaan utama, lama berternak dan jumlah anggota keluarga disajikan pada Tabel 1.

Tabel 1. Karakteristik Peternak Sapi yang Terintegrasi Perkebunan Kelapa Sawit

\begin{tabular}{llcc}
\hline & Karakteristik & Jumlah (Orang) & Persentase $(\%)$ \\
\hline \multirow{6}{*}{ Umur } & $21-30$ & 8 & 13,3 \\
& $31-40$ & 15 & 25,0 \\
& $41-50$ & 21 & 35,0 \\
& $51-64$ & 14 & 23,3 \\
& $>64$ & 2 & 3,3 \\
\hline \multirow{5}{*}{ Pendidikan } & SD & 27 & 45 \\
& SLTP & 12 & 20 \\
& SLTA & 18 & 30 \\
\multirow{2}{*}{ Pengalaman } & S1 & 3 & 5 \\
berternak & $1-5$ & 33 & 55 \\
& $6-10$ & 25 & 41,67 \\
& $11-15$ & 2 & 3,33 \\
\multirow{3}{*}{ Pekerjaan } & Petani & 51 & 85 \\
& Wiraswasta & 6 & 10 \\
& PNS & 3 & 5
\end{tabular}

Sumber: Data Primer diolah, 2020.

Umur peternak mempunyai pengaruh terhadap kemampuan untuk bekerja (Ervina et al., 2019). Berdasarkan Tabel 1 bahwa 96,63\% peternak sapi yang terintegrasi perkebunan kelapa sawit tergolong tenaga kerja dalam batas usia produktif 14-64 tahun. Kondisi ini berarti masih memungkinkan untuk peningkatan keterampilan dalam memelihara ternak sebab kelompok usia tersebut umumnya dicirikan dengan kondisi fisik dan kemampuan berpikir yang masih cukup kuat.

Tingkat pendidikan seseorang menunjukkan kecepatan peternak dalam menyerap atau menerima informasi maupun inovasi akan berpengaruh pada tingkat produktivitas (Nurlaila \& Zali, 2020). Tingkat pendidikan, peternak sapi di Kecamatan Wiwirano yaitu mayoritas pendidikan setingkat SD. Peternak yang mencapai pendidikan SLTP sebesar 20\% dan 30\% mencapai pendidikan SLTA. Secara umum tingkat pendidikan masih tergolong rendah. Selanjutnya, rata-rata pengalaman peternak dalam memelihara sapi di lokasi penelitian adalah 5,82 tahun dengan kisaran 2 sampai 15 tahun. Mayoritas pengalaman responden berada pada kategori tinggi. Tenaga kerja akan menjadi lebih terampil jika mempunyai kecakapan dan pengalaman yang cukup (Pinardi et al., 2020).

Jenis pekerjaan utama erat kaitannya dengan upaya mengoptimalkan produktivitas suatu usaha (Fadli \& Satriawan, 2018). Peternak sapi bali yang terintegrasi kelapa sawit 
mengusahakan peternakan sapi potong sebagai mata pencaharian sampingan. Ada $8 \%$ peternak mempunyai mata pencaharian utama sebagai petani dimana beternak sebagai usaha sambilan, $10 \%$ memiliki pekerjaan utama sebagai wiraswasta dan 5\% sisanya bekerja di luar pertanian dan wiraswasta.

\section{Curahan Waktu Tenaga Kerja Keluarga}

Curahan tenaga kerja keluarga merupakan besarnya waktu yang digunakan peternak untuk melakukan suatu kegiatan yang dikonversikan dalam satuan harian orang kerja (HOK). Curahan waktu tenaga kerja keluarga pada usaha ternak sapi Bali dan kebun kelapa sawit di Kecamatan Wiwirano dilihat pada Tabel 2.

Tabel 2. Curahan Tenaga Kerja Keluarga Usaha Ternak Sapi Bali dan Kelapa Sawit

\begin{tabular}{llccccc}
\hline \multirow{2}{*}{ Jenis usaha } & \multirow{2}{*}{ Jenis kegiatan } & \multicolumn{2}{c}{ Curahan waktu kerja(HOK) } & \multicolumn{2}{c}{ Total } \\
\cline { 3 - 7 } & & $\mathbf{L}$ & $\mathbf{P}$ & $\mathbf{A}$ & HOK & (Jam/Hari) \\
\hline \multirow{2}{*}{ Sapi bali } & Memberi pakan & 0,190 & 0,067 & 0,004 & 0,261 & 2,254 \\
& Memberi minum & 0,095 & 0,034 & 0,002 & 0,131 & 1,127 \\
& Menggembalakan ternak & 0,143 & 0,050 & 0,003 & 0,196 & 1,691 \\
& Pemeriksaan kesehatan & 0,048 & 0,017 & 0,001 & 0,065 & 0,564 \\
\hline Total & & 0,475 & 0,168 & 0,010 & 0,653 & 5,635 \\
\hline Kelapa sawit & Pemupukan & 0,119 & 0,054 & 0,004 & 0,177 & 1,557 \\
& Penyulaman & 0,178 & 0,081 & 0,006 & 0,266 & 2,336 \\
& Pemberantasan hama & 0,226 & 0,103 & 0,008 & 0,336 & 2,959 \\
& Pemanenan & 0,250 & 0,114 & 0,008 & 0,372 & 3,270 \\
\hline \multicolumn{1}{c}{ Total } & & 0,773 & 0,352 & 0,026 & 1,151 & 10,121 \\
\hline
\end{tabular}

Keterangan $\quad: \mathrm{L}=$ Laki-laki; $\mathrm{P}=$ Perempuan; $\mathrm{A}=$ Anak-anak

Sumber : : Data primer diolah, 2020.

Hasil analisis pada Tabel 2 menunjukkan bahwa curahan tenaga kerja keluarga dalam usaha ternak sapi bali di Kecamatan Wiwirano sebesar 0,653 HOK atau membutuhkan waktu sebesar 5,635 jam/hari. Pakan yang diberikan berupa pakan hijauan. Pekerjaan ini lebih banyak dilakukan oleh tenaga kerja keluarga laki-laki dewasa dengan pemberian pakan ternak menggunakan waktu sebesar 2,254 jam/hari atau 0,261 HOK.

Pemberian air minum dilakukan secara ad libitum, peternak biasanya menyiapkan tempat minum untuk ternak. Sehingga, untuk curahan waktu kerja dalam pemberian air minum di Kecamatan Wiwirano sebesar 1,12 jam/hari atau sebesar 0,131 HOK. Penggembalaan ternak merupakan kegiatan melepas ternak pada suatu area untuk mencari pakan sendiri (H. Hidayat et al., 2020). Pekerjaan ini biasanya dilakukan dengan bersamaan dengan memindahkan ternak dari suatu area ke area lain. Hasil Penelitian menunjukkan bahwa penggembalaan ternak di Kecamatan Wiwirano membutuhkan waktu sebesar 1,691jam/hari atau sebesar 0,196 HOK.

Pemeriksaan kesehatan ternak adalah salah satu cara mengetahui kondisi ternak sehingga dilakukan penanganan terhadap gejala dan penyakit pada ternak (Matondang \& Talib, 2015). Biasanya peternak melakukan pemeriksaan kesehatan ternak hanya berdasarkan pada pengamatan secara langsung sesuai dengan kondisi fisik ternak (Samberi et al., 2012). Hasil penelitian curahan waktu kerja dalam pemeriksaan kesehatan di Kecamatan Wiwirano sebesar 0,564 jam/hari atau membutuhkan curahan waktu tenaga kerja sebesar 0,065 HOK. Curahan tenaga kerja keluarga dalam usaha kelapa sawit di Kecamatan Wiwirano sebesar 1,151 HOK atau membutuhkan waktu sebesar 10,121 jam/hari. Pemupukan merupakan kunci untuk 
mendapatkan hasil panen yang optimal dan tentunya melimpah (Hidayat et al., 2020). Berdasarkan hasil penelitian bahwa curahan waktu kerja keluarga dalam kegiatan pemberian pupuk di Kecamatan Wiwirano sebesar 1,557 jam perhari $(0,177 \mathrm{HOK})$.

Penyiangan merupakan kegiatan yang dilakukan oleh petani untuk mencabut membersihkan gulma serta digunakan untuk membuka daun kelapa sawit yang sudah layu (Umiyati \& Kurniadie, 2018). Berdasarkan hasil penelitian bahwa curahan waktu kerja keluarga dalam kegiatan pemberian pupuk di Kecamatan Wiwirano sebesar 2,336 jam perhari (0,266 HOK). Pemberantasan hama adalah usaha memusnahkan, membunuh hama yang umumnya dilakukan dengan pestisida kimia secara preventif (Agustira et al., 2019). Pemberantasan hama yang dilakukan di lokasi penelitian secara umum menggunakan pestisida dengan cara penyemprotan secara menyeluruh. Hasil penelitian bahwa curahan waktu kerja rumah tangga dalam kegiatan pemberantasan hama di Kecamatan Wiwirano sebesar 2,959 jam/hari (0,336 HOK). Pemanenan merupakan kegiatan akhir dari proses produksi di lapangan dan faktor penentu proses selanjutnya (Pratiwi et al., 2019). Sementara itu, curahan waktu kerja rumah tangga dalam kegiatan pemanenan di Kecamatan Wiwirano sebesar 3,270 jam/hari (0,372 HOK).

\section{Produktivitas Tenaga Kerja Keluarga}

Rata-rata produktivitas teknis dan ekonomis tenaga kerja pada usaha temak sapi yang terintegrasi perkebunan kelapa sawit di Kecamatan Wiwirano disajikan pada Tabel 3.

Tabel 3. Produktivitas Tenaga Kerja Keluarga Usaha Ternak Sapi Terintegrasi Kelapa Sawit

\begin{tabular}{lll}
\hline \multirow{2}{*}{ Produktivitas } & \multicolumn{2}{c}{ Usaha } \\
\cline { 2 - 3 } & Ternak Sapi & \multicolumn{1}{c}{ Kelapa Sawit } \\
\hline Teknis & $4,72(\mathrm{ST} / \mathrm{HOK})$ & $133,69(\mathrm{~kg} / \mathrm{HOK})$ \\
Ekonomis & $83.983,43(\mathrm{Rp} / \mathrm{HOK})$ & $120.772,75(\mathrm{Rp} / \mathrm{HOK})$ \\
\hline
\end{tabular}

Sumber : Data primer diolah, 2020

Hasil analisis pada Tabel 3 menunjukkan bahwa rata-rata produktivitas teknis tenaga kerja untuk usaha sapi sebesar 4,72 ST/HOK, artinya setiap satu HOK tenaga kerja mampu menangani 4,72 satuan ternak dalam satu hari. Sedangkan untuk produktivitas teknis tenaga kerja keluarga usaha kelapa sawit adalah 133,69 kg/HOK artinya setiap 1 HOK mampu menangani 133,69 Kg kelapa sawit dalam 1 hari. Rata-rata produktivitas ekonomis tenaga kerja keluarga usaha sapi bali Rp. 83.983,43/HOK berarti sumbangan tenaga kerja keluarga pada usaha peternakan sapi sebesar Rp 83.983,43 setiap harinya. Rata-rata produktivitas ekonomis tenaga kerja keluarga usaha kelapa sawit yaitu sebesar Rp. 120.772,75/HOK. Artinya bahwa setiap HOK memperoleh pendapatan sebesar Rp.120.772,75 dalam 1 hari. Pendapatan untuk setiap keterlibatan tenaga kerja keluarga dinyatakan pula sebagai produktivitas tenaga kerja keluarga (Suharno et al., 2017). Hal ini berarti bahwa produktivitas tenaga kerja keluarga pada usaha kebun kelapa sawit berdasarkan perhitungan produktivitas teknis dan ekonomis lebih tinggi daripada usaha ternak sapi Bali.

Produktivitas tenaga kerja keluarga pada usaha kebun kelapa sawit lebih tinggi dari pada usaha ternak sapi bali. Hal ini disebabkan faktor teknis dan faktor ekonomis dari masingmasing usaha. Faktor teknis yang dimaksud adalah pekerjaan utama dan siklus produksi. Secara umum, peternak sapi bali di Kecamatan Wiwirano melakukan usaha ternak sapi bali sebagai usaha sampingan dan usaha kelapa sawit sebagai usaha utama sehingga menyebabkan 
produktivitas tenaga kerja pada usaha sapi bali relatif lebih rendah. Siklus produksi yang dimaksud adalah kelapa sawit relatif lebih cepat produksi dibanding ternak sapi bali.

Faktor ekonomis juga memiliki kaitan dengan produktivitas tenaga kerja karena faktor ekonomis yang mempengaruhi produktivitas tenaga kerja adalah penerimaan dan aspek pasar (Khairunisa, 2017). Usaha kelapa sawit memiliki pemasaran yang cukup terjamin di Kecamatan Wiwirano, sehingga hasil produksi setelah panen dari usaha kelapa sawit dapat langsung dijual kepada perusahaan yang menampung hasil panen kelapa sawit. Sedangkan usaha ternak sapi bali belum memiliki pemasaran yang jelas sehingga peternak harus mencari pembeli atau menawarkan ternaknya. Pada usaha ternak sapi bali yang terintegrasi kelapa sawit di Kecamatan Wiwirano memberikan penerimaan yang lebih besar dari usaha kelapa sawit dibanding usaha ternak sapi bali. Hal ini disebabkan aspek pasar usaha kelapa sawit lebih terjamin dan siklus produksi yang cepat sehingga perekonomian peternak lebih cepat.

\section{KESIMPULAN DAN SARAN}

Produktivitas curahan tenaga kerja keluarga pada usaha ternak sapi bali adalah sebesar 4,72 ST/HOK dan produktivitas ekonomis sebesar Rp. 83.983,43/HOK. Sedangkan produktivitas curahan tenaga kerja keluarga pada usaha kebun kelapa sawit adalah sebesar 133,69 kg/HOK dan produktivitas ekonomis sebesar Rp. 120.772,75/ HOK.

\section{DAFTAR PUSTAKA}

Agustira, M. A., Siahaan, D., \& Hasibuan, H. A. (2019). Nilai Ekonomi Nira Sawit Sebagai Potensi Pembiayaan Peremajaan Kebun Kelapa Sawit Rakyat. Jurnal Penelitian Kelapa Sawit, 27(2), 115-126.

Anggara, A. (2019). Dampak Kesehatan Keselamatan Kerja Dan Komitmen Organisasi Terhadap Kinerja Buruh Pada Pt. Hok Tong. Tesis. Universitas Sriwijaya. Palembang. repository.um-palembang.ac.id.

Badan Pusat Statistik Kabupaten Konawe Utara. (2020). Populasi Ternak , Luas Lahan dan Produktivitas Perkebunan Kelapa Sawit. Konawe Utara, Sulawesi Tenggara. ID.

Efendi, N., Hendri, E., \& Kurniawan., M. (2020). Pengaruh Motivasi Kerja Dan Disiplin Kerja Terhadap Produktivitas Kerja Karyawan Pada PT Hok Tong Plaju Palembang. Jurnal Manjemen dan Investasi. 2(1), 76-93.

Ervina, D., Setiadi, A., \& Ekowati, T. (2019). Analisis Faktor-Faktor Yang Mempengaruhi Pendapatan Usaha Ternak Sapi Perah Kelompok Tani Ternak Rejeki Lumintu Di Kelurahan Sumurrejo Kecamatan Gunungpati Semarang. Soca: Jurnal Sosial Ekonomi Pertanian, 13(2), 188-200.

Fadli, C., \& Satriawan, H. (2018). Analysis of the Potential Integration of Palm Oil-Cattle in Bireuen Regency, Aceh Province. AGRARIS: Journal of Agribusiness and Rural Development Research, 4(2). 69-80.

Hidayat, F., Syarovy, M., Pradiko, I., \& Rahutomo, S. (2020). Aplikasi Kotoran Sapi untuk Perbaikan Sifat Kimia Tanah dan Pertumbuhan Vegetatif Bibit Kelapa Sawit (Elaeis guineensis Jacq.) pada Media Sub Soil. Jurnal Penelitian Kelapa Sawit, 28(1), 51-58. 
SEA Volume 10, No. 01, June 2021

Hidayat, H., Pagala, M. A., \& Zulkarnain, D. (2020). Basis Pengembangan Kawasan Sapi Potong Berdasarkan Luas Tanaman Perkebunan dan Tanaman Pangan di Kabupeten Muna. Jurnal Sosio Agribisnis, 5(1), 43-49.

Khairunisa, G. R. (2017). Daya Saing Minyak Sawit Dan Dampak Renewable Energy Directive (Red) Uni Eropa Terhadap Ekspor Indonesia Di Pasar Uni Eropa. Jurnal Agribisnis Indonesia, 5(2), 125-136.

Matondang, R. H., \& Talib, C. (2015). Integrated Bali Cattle Development Model Under Oil Palm Plantation. WARTAZOA, 25(3), 147-157.

Nurlaila, S., \& Zali, M. (2020). Faktor Mempengaruhi Peningkatan Populasi Sapi Madura di Sentra Sapi Sonok Kabupaten Pamekasan. Jurnal Ilmu Dan Teknologi Peternakan Tropis, 7(1), 21-28.

Pagala, M. A., Munadi., L. M., Zulkarnain, D. (2019). Diversity and Green Types Carrying Capacity Bali Beef in Oil Palm Plantation In Kolaka District. Indonesian Journal of Animal Agricultural Science, 1(1), 48-55.

Pagala, M. A., Zulkarnain, D., \& Munadi, L. O. M. (2020). Kapasitas Daya Tampung Hijauan Pakan Ternak dan Hasil Ikutan Perkebunan Kelapa Sawit di Kecamatan Tanggetada Kabupaten Kolaka. Jurnal Sosio Agribisnis, 5(2), 70-76.

Pinardi, D., Mulyono, D., Wahyuni, D. S., \& Surachman, M. (2020). Development of palm oil-cattle integration program to support self-sufficiency of beef and development of human resources. Jurnal Ilmu-Ilmu Peternakan, 30(1), 40-49.

Pratiwi, D. A., Maryam, S., \& Balkis, S. (2019). Analisis Pendapatan Usahatani Kelapa Sawit (Elaeis Guineensis Jacq.) Di Kecamatan Waru Kabupaten Penajam Paser Utara (Income Analysis of Oil Palm Farming (Elaeis guineensis Jacq.) in Waru Subdistrict, Penajam Paser Utara District). Jurnal Agribisnis Dan Komunikasi Pertanian (Journal of Agribusiness and Agricultural Communication), 3(1), 9-16.

Rusnan, H.-, Kaunang, C. L., \& Tulung, Y. L. R. (2015). Analisis Potensi Dan Strategi Pengembangan Sapi Potong Dengan Pola Integrasi Kelapa-Sapi Di Kabupaten Halmahera Selatan Provinsi Maluku Utara. Zootec, 35(2), 187-200.

Samberi, K. Y., Ngadiyono, N., \& Sumadi, S. (2012). Estimasi Dinamika Populasi dan Produktivitas Sapi Bali di Kabupaten Kepulauan Yapen, Propinsi Papua (Estimation of the Dynamics of Population and Productivity of Bali Cattle in Kepulauan Yapen Regency, Papua Province). Buletin Peternakan, 34(3), 169-177.

Setiawan, B. D., Arfa'i, A., \& Nur, Y. S. (2019). Evaluasi Sistem Manajemen Usaha Pembibitan Sapi Bali Terintegrasi Dengan Perkebunan Kelapa Sawit Di Kabupaten Pasaman Barat, Provinsi Sumatera Barat. Jurnal Ilmiah Peternakan Terpadu, 7(3), 276-286. 
Sirait, P., Lubis, Z., \& Sinaga, M. (2015). Analisis Sistem Integrasi Sapi Dan Kelapa Sawit Dalam Meningkatkan Pendapatan Petani Di Kabupaten Labuhanbatu. Agrica (Jurnal Agribisnis Sumatera Utara), 8(1), 1-15.

Suharno, S., Yuprin A.D., Y. A. D., \& Barbara, B. (2017). Analisis Kinerja Usahatani Perkebunan Kelapa Sawit Rakyat Melalui Pola Kemitraan di Provinsi Kalimantan Tengah. Jurnal Agribisnis Indonesia, 3(2), 135-144.

Tatipikilawan J.M. 2012. Analisis Produktivitas Tenaga Kerja Keluarga Pada Usaha Peternakan Kerbau di Pulau Moa Kabupaten Maluku Baratdaya. Jurnal Agroforestri 7(1): 9-10.

Umiyati, U., \& Kurniadie, D. (2018). Pengendalian Gulma Umum Dengan Herbisida Campuran (Amonium Glufosinat $150 \mathrm{~g} / \mathrm{l}$ dan Metil Metsulfuron $5 \mathrm{~g} / \mathrm{l}$ ) Pada Tanaman Kelapa Sawit TBM. Jurnal Penelitian Kelapa Sawit, 26(1), 29-35.

Zulkarnain, D., Munadi, L. M., Pagala, M. A., \& Obi, M. (2020). Bali Cattle Development Strategy Based On The Results Of Palm Oil Plantation In Kolaka District. Indonesian Journal of Animal Agricultural Science, 2(1), 88-97. 